\title{
Penurunan Nyeri Persalinan Primigravida Kala I Fase Aktif Pascapenghirupan Aromaterapi Lavender
}

\author{
Tarsikah, ${ }^{1}$ Herman Susanto, ${ }^{2}$ Herri S. Sastramihardja ${ }^{3}$ \\ ${ }^{1}$ Jurusan Kebidanan Politeknik Kesehatan Kemenkes Malang, ${ }^{2}$ Departemen Obstetri Ginekologi, \\ ${ }^{3}$ Departemen Farmakologi Fakultas Kedokteran Universitas Padjadjaran \\ Rumah Sakit Dr. Hasan Sadikin Bandung
}

\begin{abstract}
Abstrak
Nyeri persalinan merupakan bagian pada proses normal yang tidak jarang menyebabkan stres fisiologis dan psikologis terhadap ibu yang berdampak pada ibu maupun janin. Sebagian besar persalinan (90\%) disertai nyeri, bahkan sampai nyeri berat. Penanganan nonfarmakologi merupakan salah satu alternatif untuk mengurangi nyeri persalinan. Penelitian ini bertujuan untuk menganalisis efek analgesik penghirupan aromaterapi lavender pada nyeri persalinan primigravida kala I fase aktif. Rancangan yang digunakan adalah studi praeksperimental, satu kelompok diobservasi sebelum dan sesudah perlakuan terhadap 30 ibu bersalin di Rumah Bersalin (RB) Kasih Ibu Jatirogo kabupaten Tuban provinsi Jawa Timur sebagai sampel yang dipilih secara konsekutif. Pengukuran variabel menggunakan skala nyeri numerik. Dilakukan analisis univariabel kuantitatif untuk mengetahui nyeri sebelum dan sesudah perlakuan. Analisis kuantitatif bivariabel Wilcoxon signed ranks test digunakan untuk mengetahui pengurangan nyeri dengan tingkat kemaknaan $\mathrm{p}<0,05$. Penelitian ini dilakukan periode 14 September-31 Oktober 2009. Hasil analisis univariabel menyatakan bahwa skor nyeri rata-rata sebelum perlakuan 7,3 (SD 1,1) dan sesudah perlakuan 5,9 (SD 1,4). Hasil uji Wilcoxon signed ranks test menunjukkan pengurangan nyeri yang bermakna pascapenghirupan aromaterapi lavender $(Z=-4,338 ; p=0,000)$. Simpulan, terdapat pengurangan nyeri persalinan pascapenghirupan aromaterapi lavender. [MKB. 2012;44(1):19-25].
\end{abstract}

Kata kunci: Nyeri persalinan, penghirupan aromaterapi lavender

\section{Labor Pain Reduction in Primigravida Active Phase after Inhalation of Lavender Aromatherapy}

\begin{abstract}
Labor pain is part of a normal process, which often causes physiological and psychological stress to mother. These stress have impact to both mother and fetus. Largely $(90 \%)$ labor comes with pain and in some cases severe pain. Non-pharmacological approach is one of alternatives to reduce labor pain. This research aims to analyse the analgesic effect of lavender aromatherapy inhalation on labor pain in primigravida in the active phase. The study was pra-experimental by observing one group before and after treatment. The group involved 30 parturients in RB Kasih Ibu Jatirogo district of Tuban, East Java. The sampling method was based on consecutive admission. The variables were measured by using numerical rating scales (NRS). Univariable quantitative analysis was applied to describe the pain before and after treatment. Wilcoxon signed ranks test bivariable quantitative analysis was used to investigate pain relief with significance level of $p<0.05$. The univariable analysis result revealed that mean pain score before treatment was 7.3 (SD 1.1) and after treatment 5.9 (SD 1.4). Wilcoxon signed ranks test result showed significant pain relief after lavender aromatherapy inhalation $(Z=-4.338, p=0.000)$. The research shows that there is a reduction of labor pain after lavender aromatherapy inhalation. [MKB. 2012;44(1):19-25].
\end{abstract}

Key words: Inhalation lavender aromatherapy, labor pain

Korespondensi: Tarsikah, Jurusan Kebidanan Politeknik Kesehatan Kemenkes Malang, jalan Besar Ijen 77C Malang 65112 Jawa Timur, telepon (0341) 551265, mobile081334443299, e-mail sikah_she@yahoo.co.id 


\section{Pendahuluan}

Persalinan merupakan proses fisiologi yang menyertai kehidupan hampir setiap wanita yang pada umumnya menakutkan, karena disertai nyeri bahkan terkadang menimbulkan kondisi fisik dan mental yang mengancam jiwa. Nyeri persalinan sendiri sebenarnya merupakan nyeri akibat kontraksi miometrium disertai mekanisme perubahan fisiologis dan biokimiawi. Di samping faktor fisik, faktor psikologis dan emosi, motivasi juga mempengaruhi timbulnya nyeri persalinan. ${ }^{1}$ Nyeri persalinan mengakibatkan rasa takut dan stres. Stres pada ibu akan menyebabkan pengeluaran hormon stres seperti katekolamin dan steroid sehingga mengakibatkan pengurangan aliran darah ibu ke janin. Nyeri hebat dan kontinu akibat kontraksi rahim dapat menimbulkan perubahan fisiologis tubuh yang bermakna (hiperventilasi 4-20 kali normal) dengan alkalosis berat, kenaikan curah jantung (50-150\%), kenaikan tekanan darah (20-40\%), kenaikan metabolisme dan konsumsi oksigen, sedangkan motilitas saluran pencernaan dan buli-buli menurun. Untuk mengurangi efek stres fisiologis maupun psikologis akibat nyeri persalinan dapat dilakukan melalui penanganan nonfarmakologi dengan cara penghirupan aromaterapi lavender, karena tidak memberikan efek invasif tetapi aman bagi ibu maupun bayi., ${ }^{2,3}$ Aromaterapi lavender merupakan metode pengobatan alami dengan menggunakan minyak esensial yang berasal dari sari tumbuhan lavender dengan pengenceran tertentu.

Dengan melakukan penelitian ini diharapkan dapat diketahui apakah aromaterapi lavender yang diberikan secara penghirupan dapat menurunkan nyeri persalinan pada primigravida kala I fase aktif.

\section{Metode}

Penelitian ini menggunakan metode praeksperimental dengan one group pre- and post-test, yaitu melakukan observasi sebanyak dua kali sebelum perlakuan dan sesudah perlakuan. Ibu in partu kala I diukur tingkat nyeri (pre-test), kemudian dilakukan penghirupan aromaterapi lavender dan selanjutnya dilakukan post-test dengan mengukur kembali tingkat nyerinya.

Penelitian ini dilakukan di Rumah Bersalin (RB) Kasih Ibu Jatirogo Kabupaten Tuban Provinsi Jawa Timur periode 14 September-31 Oktober 2009. Populasi penelitian ini adalah primigravida usia kehamilan aterm, in partu yang akan melahirkan di RB Kasih Ibu Jatirogo Kabupaten Tuban. Teknik pengambilan sampel yang digunakan yaitu konsekutif sampling, besar sampel ditentukan dengan rumus estimasi rerata dua kelompok berpasangan yang sebelumnya dilakukan penelitian pendahuluan pada 5 primigravida in partu dan jumlah sampel sebanyak 30 in partu kala I fase aktif.

Alat dan bahan yang dipergunakan dalam penelitian ini adalah lembar observasi nyeri skala numerik (numeric rating scale/NRS), tisu makan, dan aromaterapi lavender dengan konsentrasi 1\%. Numeric rating scale merupakan garis horizontal dengan skala angka mulai dari 0 sampai dengan 10, angka 0 menunjukkan tidak ada nyeri, $1-3$ nyeri ringan (secara objektif klien dapat berkomunikasi dengan baik), 4-6 nyeri sedang (secara objektif klien mendesis, menyeringai, dapat menunjukkan lokasi nyeri, mendeskripsikannya, dan dapat mengikuti perintah dengan baik), 7-9 nyeri berat (secara objektif klien terkadang tidak dapat mengikuti perintah tetapi masih respons terhadap tindakan, dapat menunjukkan lokasi nyeri, tidak dapat mendeskripsikan, tidak dapat diatasi dengan alih posisi, napas panjang, dan distraksi), dan 10 nyeri hebat (klien sudah tidak mampu lagi berkomunikasi dan memukul). Penilaian tingkat nyeri dilakukan dengan cara ibu in partu kala I fase aktif diminta untuk melingkari angka pada NRS untuk menggambarkan nyeri yang dirasakan sebelum penghirupan aromaterapi lavender. Aromaterapi lavender berasal dari minyak esensial lavender murni (Lavandula officinalis) produksi MB sebanyak 0,4 mL diencerkan dengan minyak karier zaitun (Virgin olive oil) sebanyak $30 \mathrm{~mL}$ yang diteteskan pada tisu makan sebanyak 3 tetes. Tisu makan yang telah ditetesi aromaterapi lavender dihirup sebanyak $3 x$ tarikan napas dalam $1 x$ his yang diulangi setiap menjelang his, dalam pengamatan 30 menit selama kala I fase aktif. Setelah 30 menit dilakukan penilaian tingkat nyeri dengan cara ibu in partu melingkari kembali angka pada NRS untuk menggambarkan tingkat nyeri setelah perlakuan penghirupan aromaterapi lavender.

Data hasil penelitian dianalisis secara deskriptif untuk melihat gambaran distribusi responden menurut karakteristik usia, pendidikan, perencanaan kehamilan, pendamping persalinan, pembukaan serviks, hasil luaran neonatus yang meliputi berat badan lahir bayi, dan nilai skor APGAR pada menit 1 dan 5. Wilcoxon signed ranks test dilakukan untuk mengetahui pengurangan nyeri persalinan sesudah perlakuan penghirupan aromaterapi lavender.

\section{Hasil}

Subjek yang dilibatkan dalam penelitian ini adalah primigravida in partu kala I fase aktif sebanyak 30 orang. Terhadap subjek penelitian diberikan perlakuan penghirupan aromaterapi 
Tabel 1 Distribusi Frekuensi Karakteristik Primigravida In Partu Kala I Fase Aktif

\begin{tabular}{cr}
\hline Karakteristik & n \\
\hline Usia (tahun) & 11 \\
$17-21$ & 11 \\
$22-26$ & 8 \\
$27-31$ & \\
Mean : 22,8 (SD 4,0) & \\
Tingkat pendidikan & 9 \\
SD & 8 \\
SMP & 13 \\
SMU & 30 \\
Perencanaan kehamilan & 0 \\
Direncanakan & \\
Tidak direncanakan & 10 \\
Pendamping persalinan & 19 \\
Suami & 1 \\
Keluarga (ibu/mertua) & 30 \\
Suami dan keluarga & \\
Jumlah &
\end{tabular}

lavender selama 30 menit.

Karakteristik primigravida antara lain bahwa usia primigravida in partu 17-31 tahun, tingkat pendidikan terbanyak SMU, semua responden merencanakan kehamilannya dan sebagian besar pendamping persalinan adalah keluarga (ibu, ibu mertua) (Tabel 1).

Primigravida in partu memperlihatkan pembukaan serviks minimal $4 \mathrm{~cm}$ dan maksimal $9 \mathrm{~cm}$ dengan pembukaan rata-rata: $6(\mathrm{SD} 1,4) \mathrm{cm}$ (Gambar 1).
Berat badan lahir bayi didominasi oleh berat badan lahir 3.000-3.500 gram. Primigravida in partu yang melahirkan bayi dengan asfiksia sedang (nilai SA 4-6) pada menit 1 sebanyak 1 orang dan semua bayi yang dilahirkan pada menit 5 mempunyai nilai skor APGAR normal.

Setelah penghirupan aromaterapi frekuensi nyeri hebat dari $1 / 30$ orang menjadi 0 , nyeri berat dari $21 / 30$ menjadi $10 / 30$ orang dan selebihnya mengalami nyeri sedang (Tabel 3). Skor nyeri ratarata sebelum perlakuan 7,3 (SD 1,1) dan sesudah perlakuan 5,9 (SD 1,4).

Skor nyeri persalinan sebelum perlakuan penghirupan aromaterapi minimal 5 (nyeri sedang) dan maksimal 10 (nyeri hebat), sedangkan sesudah penghirupan aromaterapi minimal 4 (nyeri sedang) dan maksimal 8 (nyeri berat). Enam responden mengalami nyeri yang tetap dan 24 responden mengalami pengurangan nyeri persalinan (Gambar 2).

Hasil analisis statistik Wilcoxon signed ranks test untuk mengetahui perubahan nyeri sebelum dan sesudah perlakuan penghirupan aromaterapi didapatkan nilai $Z=-4,388$ dan $p=0,000$.

\section{Pembahasan}

Karakteristik subjek yang terlibat dalam penelitian dikategorikan berdasarkan usia, tingkat pendidikan, perencanaan kehamilan, pendamping persalinan pembukaan serviks, dan hasil luaran neonatus yaitu berat badan lahir serta nilai skor APGAR pada menit 1 dan 5 .

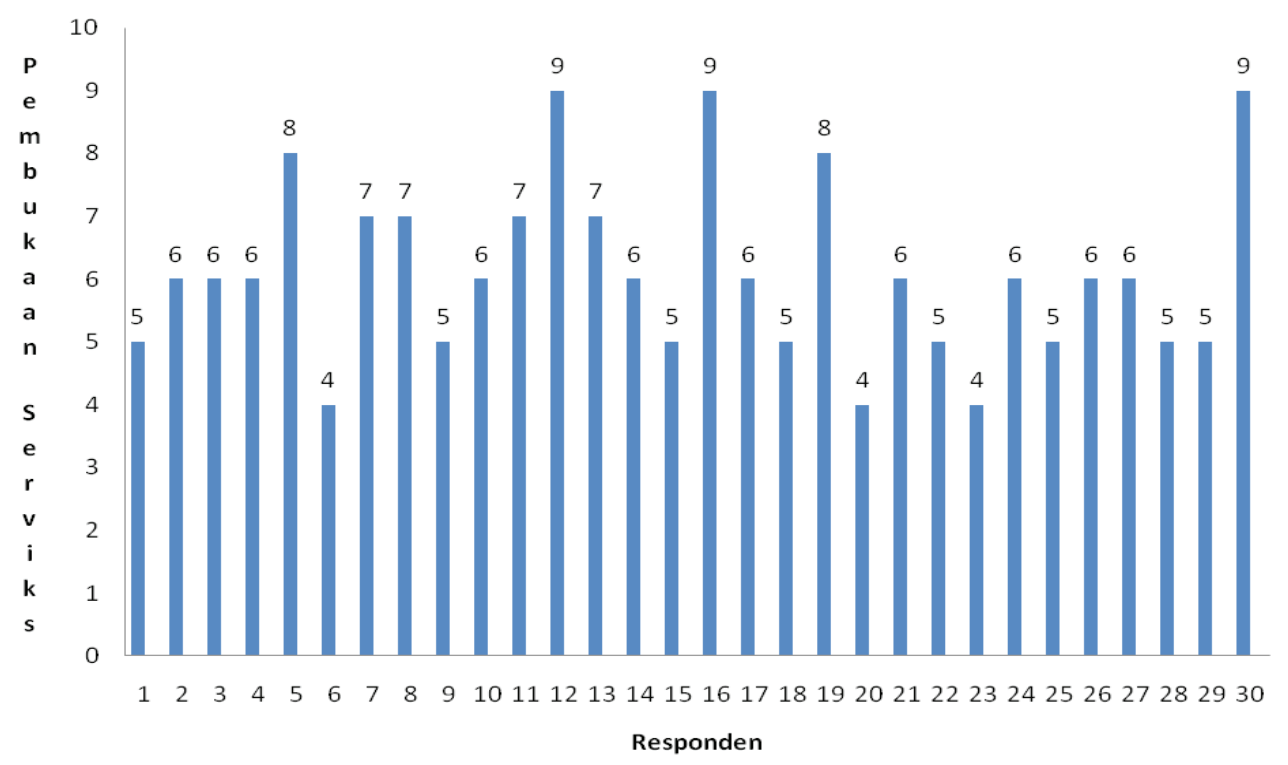

Gambar 1 Karakteristik Pembukaan Serviks 
Tabel 2 Karakteristik Hasil Luaran Neonatus

\begin{tabular}{crc}
\hline Karakteristik & n & Uji Statistik \\
\hline Berat baru lahir (gram) & 2 & Mean $(\mathrm{SD})$ \\
2.500 & 10 & $3,311(360,8)$ \\
$2.500-3.000$ & 15 & \\
$3.000-3.500$ & 3 & Mean (SD) \\
>3.500** & & $7,6(0,57)$ \\
Nilai SA menit 1 & 0 & \\
$4-6$ & 1 & Mean (SD) \\
$7-10$ & 29 & $9(1,1)$ \\
Nilai SA menit 5 & 0 & \\
$0-3$ & 0 &
\end{tabular}

Primigravida menjadi salah satu kriteria inklusi pada subjek penelitian karena paritas mempengaruhi nyeri persalinan. Pada primigravida proses pendataran serviks terjadi terlebih dahulu dibandingkan dengan pembukaan, sehingga proses lebih lama dibandingkan dengan multigravida. Proses ini akan mengakibatkan kelelahan yang dapat berpengaruh pada peningkatan persepsi nyeri. ${ }^{3,4}$

Usia subjek penelitian bervariasi antara 17 sampai dengan 31 tahun. Menurut Potter dan Perry ${ }^{18}$ salah satu faktor yang mempengaruhi pengalaman nyeri di antaranya usia. Hal ini tidak sepenuhnya terjadi pada nyeri persalinan pada subjek penelitian di RB Kasih Ibu, karena nyeri persalinan memiliki karakteristik yang unik dibandingkan dengan nyeri lainnya. Nyeri persalinan merupakan bagian dari proses yang normal, sedangkan nyeri lain pada umumnya menunjukkan kerusakan, injury atau penyakit dan parturien akan mengetahui bahwa ia akan mengalami nyeri pada saat persalinan. ${ }^{3}$ Menurut Davim dkk., ${ }^{5}$ usia berhubungan secara tidak langsung dengan nyeri persalinan karena mempengaruhi emosi seseorang dan berpengaruh pada harapan parturien terhadap perawatan selama persalinan. Kepuasan wanita terhadap proses persalinan berubah dari waktu ke waktu. Faktor yang berhubungan dengan peningkatan kepuasan ibu bersalin antara lain sikap dan perilaku tenaga kesehatan, kualitas hubungan pemberi pelayanan, dan kuantitas keikutsertaan dalam pengambilan keputusan selama persalinan. Mereka lebih menyukai lingkungan persalinan seperti rumah mereka dan mengenal dengan siapa yang melakukan perawatan. ${ }^{6}$

Pendidikan yang ditempuh subjek penelitian sebagian besar SMU, jenjang pendidikan sebagian besar sudah melampaui pendidikan dasar. Menurut

Tabel 3 Deskripsi Nyeri Sebelum dan Sesudah Perlakuan Penghirupan Aromaterapi Lavender

\begin{tabular}{crc}
\hline Nyeri & n & Uji Statistik \\
\hline Sebelum perlakuan & & Mean 7,3 (SD 1,1) \\
Ringan (1-3) & 0 & \\
Sedang (4-6) & 8 & \\
Berat (7-9) & 1 & Mean 5,9 (SD 1,4) \\
Hebat (10) & & \\
Sesudah perlakuan & 0 & \\
Ringan (1-3) & 20 & \\
Sedang (4-6) & 10 & \\
Berat (7-9) & 0 & \\
Hebat (10) & 30 & \\
Jumlah & &
\end{tabular}




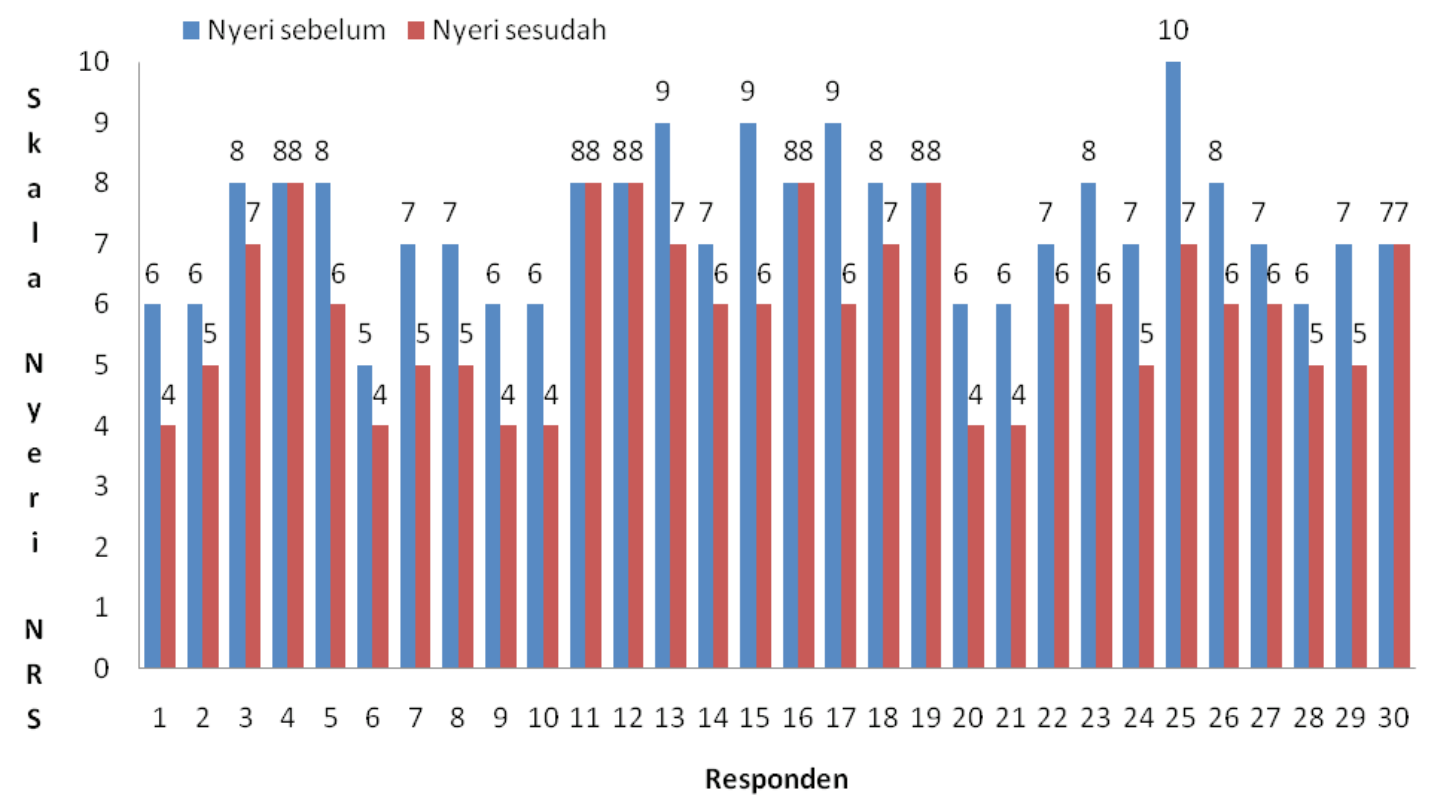

Gambar 2 Perubahan Skor Nyeri Sebelum dan Sesudah Penghirupan Aromaterapi Lavender NRS= numeric rating scale/skala numerik nyeri

Swelling dkk., pendidikan secara umum dapat mempengaruhi psikososial ibu bersalin selain persiapan dan harapan akan persalinan yang akan dijalaninya.

Semua subjek merencanakan kehamilannya. Kehamilan yang tidak diinginkan (unwanted pregnancy) akan mempengaruhi psikologis ibu (insidensi dan intensitas nyeri persalinan termasuk mental, sikap, perasaan, serta emosi parturien) saat menghadapi persalinan. ${ }^{3,8}$ Persalinan pada kehamilan yang tidak diharapkan dilaporkan menimbulkan nyeri persalinan yang lebih berat. ${ }^{9}$

Pada penelitian ini 19/30 subjek penelitian didampingi keluarga (ibu kandung atau ibu mertua). Peran ibu sebagai pendamping persalinan masih dominan di beberapa wilayah pedesaan, termasuk wilayah Jatirogo kabupaten Tuban karena permasalahan melahirkan dianggap sebagai urusan perempuan. Keberadaan pendamping persalinan dapat mempengaruhi kondisi psikologis ibu. Efek kehadiran pasangan terhadap nyeri persalinan, dinyatakan bahwa kehadiran pasangan akan memudahkan bagi ibu bersalin dalam menghadapi nyeri. ${ }^{10}$ Penelitian Ha dkk. ${ }^{11}$ di Hongkong tentang siapa yang lebih disukai ketika suami tidak dapat mendampingi saat persalinan: ibu (38\%), ibu mertua (26\%), kakak perempuan (16\%), dan lainnya: kakak ipar perempuan, bibi, keponakan, serta teman. Sebagian besar parturien $(80 \%)$ menyatakan rasa nyeri yang dirasakan berkurang.

Subjek penelitian dalam keadaan in partu pada pembukaan 4-9 $\mathrm{cm}$ dan presentasi belakang kepala. Derajat nyeri persalinan dipengaruhi oleh posisi bayi karena berkaitan proses rotasi kepala, dengan frekuensi, kekuatan, lama kontraksi uterus, dan pembukaan serviks. ${ }^{3,5,12}$

Pada hasil luaran neonatus didapatkan nilai skor APGAR pada menit 1 rata-rata 7,6 (SD 0,57) dan menit 5 rata-rata 9 (SD 1,1). Pada hasil RCTs yang dilakukan oleh Burn dkk. ${ }^{13}$ penghirupan aromaterapi lavender selama 30-40 menit memberikan hasil luaran rata-rata nilai SA pada menit 1 sebesar 9 $(\mathrm{p}=0,38), 5$ menit kedua sebesar $10(\mathrm{p}=0,92)$, dan 10 menit kemudian nilainya $10(\mathrm{p}=0,68)$.

Nyeri persalinan merupakan sensasi yang tidak menyenangkan akibat stimuli saraf sensoris. Nyeri tersebut terdiri atas 2 komponen, yaitu komponen fisiologis dan psikologis. Komponen fisiologis merupakan proses penerimaan impuls oleh saraf sensorik dan menyalurkan impuls tersebut menuju saraf pusat, sedangkan komponen psikologis meliputi rekognisi sensasi, interpretasi rasa nyeri, dan reaksi terhadap hasil interpretasi nyeri tersebut. ${ }^{3}$

Tingkat nyeri sebelum perlakuan penghirupan aromaterapi lavender meliputi nyeri sedang $8 / 30$, nyeri berat $21 / 30$, dan nyeri hebat $1 / 30$. Penelitian yang dilakukan oleh Muhadji ${ }^{9}$ dinyatakan derajat nyeri rata-rata persalinan kala I fase aktif dengan pengukuran VAS berupa derajat sedang sampai berat, skor 4-6 sampai 7-10.

Lavender merupakan salah satu minyak esensial analgesik yang mengandung $8 \%$ terpena dan $6 \%$ keton. ${ }^{14}$ Monoterpena merupakan jenis senyawa terpena yang paling sering ditemukan dalam minyak atsiri tanaman. Pada aplikasi medis monoterpena 
digunakan sebagai sedatif. Minyak lavender juga mengandung 30-50\% linalil asetat. ${ }^{15}$ Linalil asetat merupakan senyawa ester yang terbentuk melalui penggabungan asam organik dan alkohol. Ester sangat berguna untuk menormalkan keadaan emosi serta keadaan tubuh yang tidak seimbang, dan juga memiliki khasiat sebagai penenang serta tonikum, khususnya pada sistem saraf. ${ }^{14}$ Tingkat nyeri sesudah perlakuan penghirupan aromaterapi lavender: nyeri sedang 20/30 dan nyeri berat 10/30 orang. Pascapenghirupan aromaterapi lavender, skor nyeri persalinan berkurang, yaitu: sebelum perlakuan rata-rata 7,3 (SD 1,1) dan 5,9 (SD 1,4) sesudah perlakuan. Pada penelitian yang dilakukan oleh Burn dkk..$^{13}$ setelah penghirupan aromaterapi selama 30-40 menit terjadi penurunan intensitas nyeri rata-rata pada nulipara 75 (SD 19) sebelum perlakuan dan 72 (SD 18) sesudah perlakuan.

Wangi yang dihasilkan aromaterapi lavender akan menstimulasi talamus untuk mengeluarkan enkefalin, berfungsi sebagai penghilang rasa sakit alami. ${ }^{14}$ Enkefalin merupakan neuromodulator yang berfungsi untuk menghambat nyeri fisiologi. ${ }^{16,17}$ Wangi aroma Lavandula angustofolia (lavender) akan diteruskan oleh nervus olfaktorius menuju bagian otak kecil, yaitu nukleus raphe yang kemudian akan melepaskan neurokimia serotonin. ${ }^{14}$ Serotonin bekerja sebagai neuromodulator untuk menghambat informasi nosiseptif dalam medula spinalis. ${ }^{17}$ Neuromodulator ini menutup mekanisme pertahanan dengan cara menghambat pelepasan substansi P di dalam kornu dorsalis. Pelepasan neurotransmiter substansi P menyebabkan transmisi sinaps dari saraf perifer (sensori) ke saraf traktus spinotalamikus. Hal ini memungkinkan impuls nyeri ditransmisikan lebih jauh ke dalam sistem saraf pusat. ${ }^{18,19}$ Penghambatan serabut saraf yang mentransmisikan nyeri (nosiseptif) akan membuat impuls nyeri tidak dapat melalui sel transmisi (sel T), sehingga tidak dapat diteruskan pada proses yang lebih tinggi di kortek somatosensoris, transisional, dan sebagainya. ${ }^{19,20}$

Persepsi nyeri dipengaruhi oleh faktor subjektif, walaupun mekanismenya belum jelas, bahkan struktur otak yang menimbulkan persepsi tersebut juga tidak jelas, sehingga nyeri secara mendasar merupakan pengalaman subjektif. ${ }^{18,20}$ Penggunaan metode nonfarmakologi memungkinkan wanita secara maksimal menggunakan mekanisme coping alami (innate coping mechanisms) yang mereka miliki untuk mengurangi nyeri persalinan. ${ }^{13,19}$

Simpulan, penghirupan aromaterapi lavender dapat mengurangi nyeri persalinan pada primigravida kala I fase aktif. Subjek penelitian yang mengalami nyeri hebat dan nyeri berat, sesudah penghirupan aromaterapi lavender menjadi nyeri berat dan nyeri sedang. Penelitian lebih lanjut dengan desain eksperimental murni diperlukan untuk mengetahui pengaruh aromaterapi lavender pada nyeri persalinan selama kala I fase aktif dan karakteristik ibu yang berhubungan dengan nyeri persalinan. Pada penelitian ini penilaian nyeri dilakukan oleh subjek penelitian dengan NRS masih memungkinkan terjadinya bias karena nyeri bersifat sangat subjektif, sehingga perlu diupayakan penilaian nyeri menggunakan instrumen penilaian nyeri yang dilakukan oleh responden maupun peneliti.

\section{Daftar Pustaka}

1. Mulyata. Paket penyuluhan dan senam hamil mengurangi stres dan nyeri serta mempercepat penyembuhan luka persalinan: naskah pidato pengukuhan guru besar anestesiologi dan reanimatologi. Solo: Fakultas Kedokteran Universitas Sebelas Maret. [diunduh 15 Mei 2009]. Tersedia dari: http://www.uns.ac.id/cp/ penelitian.php?act=det\&idA=271.

2. Balcin ML. The safety issue in aromatherapy. Aromatherapy science; a guide for healthcare professionals. London: Pharmaceutica Press; 2006.

3. Yuliatun L. Penanganan nyeri persalinan dengan metode non-farmakologi. Malang: Bayu Media Publishing; 2008.

4. Tournaire M, Yonneau AT. Complementary and alternative approaches to pain relief during labor (review). eCAM. 2007;4(4):409-17.

5. Davim RMB, Torres GV, Melo ES. Nonpharmacological strategies on pain relief during labor: pre-testing of an instrument. Rev Latino-Am Enfermagem. 2007;15(2):1150-6.

6. Lally JE, Murtagh MJ, Macphail S, Thomson R. More in hope than expectation: a systematic review of women's expectations and experience of pain relief in labour. BMC Medicine 2008 [diunduh 9 Desember 2009]. Tersedia dari: http://www.biomedcentral.com/17417015/6/7.

7. Swelling E, Johnson, K, Allen J. How to implement complementary therapies for laboring women. MCN Am J Mat Child Nursing. 2006;31(6):364-70.

8. Lowdermilk DL, Perry SE. Maternity nursing. Edisi ke-7. St. Louis, Mo.: Mosby Elsevier; 2006.

9. Muhadji I. Pengaruh pemberian tramadol intramuskular terhadap nyeri persalinan, tekanan darah, nadi, respirasi ibu, serta bunyi jantung anak pada primigravida parturien. [Tesis]. Bandung: Program Pendidikan Dokter Spesialis I Universitas Padjadjaran; 2006.

10. Beji NK. Effects of fathers' attendance to labor and delivery on the experience of childbirth in 
Turkey. Western J Nurs Res. 2007;29(2):21331.

11. Ha LS, Chi NN, Fan WT. Significant others attending. Labor and delivery study III. [diunduh 9 Januari 2010]. Tersedia dari: http:// www.midwives.org.hk/icm conference/ presentation $/ 03 \mathrm{~N} \% 20 \mathrm{C} \% 20 \mathrm{Ng}-\mathrm{HK} . \mathrm{pdf}$.

12. Smith CA, Collins CT, Cyna AM, Crowther CA. Complementary and alternative therapies for pain management in labour (review). New York: JohnWiley \& Sons, Ltd; 2008.

13. Burn E, Zobby V, Panzery D, Oskrochi R, Regalia A. Aromatherapy in childbirth: a pilot randomized controlled trial. Br J Obstet Gynaecol. 2007;114(7):838-44.

14. Price S, Price L. Aromatherapy for health professionals. Edisi ke-2. London: Churchil
Living Stone; 2003.

15. Wiryodidagdo S. Kimia dan farmakologi bahan alami. Edisi ke-2. Jakarta: EGC; 2008.

16. Ganong WF. Dalam: Pedit BU, penerjemah. Buku ajar fisiologi kedokteran. Edisi ke-22. Jakarta: EGC; 2008.

17. Mander R. Nyeri persalinan. Jakarta: EGC; 2005.

18. Potter PA, Perry AG. Fundamental keperawatan. Konsep, proses dan praktik. Edisi ke-4. Jakarta: EGC; 2005.

19. Coad J, Dunstall M. Fisiologi persalinan. Dalam: Pedit BU, penerjemah. Anatomi fisiologi untuk bidan. Jakarta: EGC; 2007. hlm. 291-9.

20. Tamsuri A. Konsep dan penatalaksanaan nyeri. Jakarta: EGC; 2007. 